\title{
ANh IIPASLCP_99413
}

\section{Self-Organization of OPV-PEG Diblock Copolymers in THF / Water}

\author{
V. Urban ${ }^{1}$, H. H. Wang ${ }^{2}$, P. Thiyagarajan ${ }^{1}$, K. C. Littrell ${ }^{1}$, H. B. Wang ${ }^{3}$ and L.Yu ${ }^{3}$
}

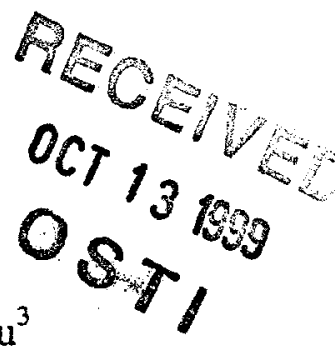

${ }^{1}$ Intense Pulsed Neutron Source and ${ }^{2}$ Chemistry and Materials Science Divisions,

Argonne National Laboratory, 9700 S. Cass Ave., Argonne, IL 60439

${ }^{3}$ Department of Chemistry, University of Chicago, Chicago, II 60637

The submitted manuscript has been created by the University of Chicago as Operator of Argonne National Laboratory ("Argonne") under Contract No. W-31-109-ENG-38 with

Contact Author: P.Thiyagarajan, thiyaga@anl.gov, Fax: (630) 252-4163

the U.S. Department of Energy. The U.S.

Government retains for itself, and others acting on its behalf, a paid-up, nonexclusive. irrevocable worldwide license in said article to reproduce, prepare derivative works, distribute copies to the public, and perform publicly and display publicly, by or on behalf of

Abstract

the Government.

Oligo(phenylenevinylene)-poly(ethyleneglycol) (OPV-PEG) diblock copolymers in tetrahydrofuran (THF) solution at concentrations of 5 to $25 \mathrm{~g} / 1$ self-assemble into rod-like structures with a radius of about $80 \AA$; for an OPV-PEG diblock copolymer comprising $13 \mathrm{PV}$ and 45 EG monomers. These aggregates consist of a liquid crystalline OPV core and a PEG shell. Addition of about $10 \%$ water to the solution induces the formation of a phase of packed rods, as revealed by a sudden and dramatic transition of the scattering pattern. Further addition of water leads to swelling and at about $30 \%$ ultimately to disruption of the packed-rod phase.

\section{Introduction}

Diblock copolymers show a wide variety of self-organization, such as cylindrical, lamellar, spherical and other structures with length scales of 100 to $1000 \AA$. These systems are very interesting not only from a fundamental point of view, but also for potential applications in the generation of nanosized structures, e.g., miniaturization of 


\section{DISCLAIMER}

This report was prepared as an account of work sponsored by an agency of the United States Government. Neither the United States Government nor any agency thereof, nor any of their employees, make any warranty, express or implied, or assumes any legal liability or responsibility for the accuracy, completeness, or usefuiness of any information, apparatus, product, or process disclosed, or represents that its use would not infringe privately owned rights. Reference herein to any specific commercial product, process, or service by trade name, trademark, manufacturer, or otherwise does not necessarily constitute or imply its endorsement, recommendation, or favoring by the United States Government or any agency thereof. The views and opinions of authors expressed herein do not necessarily state or reflect those of the United States Government or any agency thereof. 


\section{DISCLAIMER}

Portions of this document may be illegible in electronic image products. Images are produced from the best available original document. 
electronic components and devices. OPV-PEG is a novel type of rod-coil diblock copolymer, which consist of a perfectly monodisperse rigid rod-like oligo(phenylenevinylene) attached to a flexible coil-like segment of polyethylene glycol (Fig.1). The extended $\pi$-conjugation of OPV accounts for its rigidity and at the same time supplies it with interesting electro-luminescent properties. The alkyl side chains, attached at every second OPV unit, enhance the hydrophobicity and increase the solubility of OPV in organic solvents. Further, it was observed that OPV homo-oligomers in THF form liquid crystalline phases. In the present study the OPV block consisted of exactly 13 OPV. units, which equals a total block length of about $85 \AA$. The PEG moiety contained approximately 45 repeat units with a narrow polydispersity of 1.05 . Also, the influence of water on OPV-PEG solutions was studied, since previous studies indicated interesting phase transitions at different amounts of water in the system.

\section{Experiments}

The synthetic procedure for OPV-PEG diblock copolymers will be described elsewhere (Wang \& Yu, 1999). Both THF and deuterated THF (d-THF) were purchased from Aldrich. THF was freshly distilled over Na/benzophenone. d-THF (99.5 atom-\% D) was used directly without further purification from a sealed ampule. $\mathrm{D}_{2} \mathrm{O}$ (99.9 atom-\% D) also came from Aldrich and was used without further purification.

SANS experiments were carried out at the time-of-flight small-angle neutron diffractometer (SAND) at the Intense Pulsed Neutron Source of Argonne National Laboratory (Thiyagarajan et al., 1998). Pulsed neutrons, $\lambda \quad 0.5-14 \AA$, were detected at a fixed sample-to-detector distance of $2.0 \mathrm{~m}$ on a $40 \times 40 \mathrm{~cm}^{2}$ gas filled area detector containing a $128 \times 128$ array of position sensitive proportional counters. Neutron wavelengths were measured with time-of-flight by binning the pulse in 68 constant $\Delta \lambda \lambda=$ 
0.05 time channels. The instrument thus provides a useful range of momentum transfer $(Q=4 \pi \sin (\theta) / \lambda$, where $\theta$ is half the scattering angle and $\lambda$ is the wavelength of the probing neutrons) of $0.0035-0.6 \AA^{-1}$ in a single measurement. OPV-PEG solutions were prepared for SANS by weighing the appropriate amount of polymer and adding $600 \mu \mathrm{l}$ THF. Concentrations of OPV-PEG were $6,11,18$ and $24 \mathrm{~g} / \mathrm{l}$ (g polymer per $1 \mathrm{~d}-\mathrm{THF}$ ). The clear, yellow solutions were inserted in cylindrical Suprasil Quartz cells of $2 \mathrm{~mm}$ path length and $20 \mathrm{~mm}$ inner diameter. SANS measurements were carried out at ambient temperature and exposure time for each measurement on SAND was two hours. The influence of water was studied in two different series. Using a $\mu$ l-syringe, aliquots of $18 \mu \mathrm{l} \mathrm{D}_{2} \mathrm{O}$ were progressively added to sample 3 , containing $24 \mathrm{~g} / \mathrm{OPV}-\mathrm{PEG}$, thus each time increasing the amount of water by $3 \%$ of the initial volume of $600 \mu 1$. After each addition, $\mathrm{D}_{2} \mathrm{O}$ was dispersed by shaking the cell, the optical appearance of the sample was monitored and the scattering pattern recorded. In the same way, $\mathrm{H}_{2} \mathrm{O}$ was added to sample 4 , containing initially $18 \mathrm{~g} / \mathrm{O}$ OPV-PEG. Table 1 summarizes all SANS experiments performed in this study.

Additionally, SAXS experiments on OPV-PEG solutions in THF were carried out at the ASAXS instrument on the BESSRC ID-12 beamline of Argonne National Laboratory's Advanced Photon Source (Seifert, Winans, Tiede \& Thiyagarajan, 1999). Sample to detector distance was $3 \mathrm{~m}$ and energy of $\mathrm{x}$-ray radiation was set to $13.5 \mathrm{keV}$. Data were collected on a CCD camera and exposure times were $1-2$ seconds for each measurement.

For each measurement about $50 \mu \mathrm{l}$ of sample solution were inserted in a quartz capillary (Mark tube) of $1.5 \mathrm{~mm}$ diameter. Starting with an initial $200 \mu \mathrm{l}$ of $22 \mathrm{~g} / \mathrm{OPV}-\mathrm{PEG}$ solution, again a series of measurements with increasing $\mathrm{H}_{2} \mathrm{O}$ content was performed. In order to preserve OPV-PEG material, the solution from a previous measurement was 
recovered from the Mark cell, remixed with the stock solution and $10 \mu \mathrm{l} \mathrm{H}_{2} \mathrm{O}$ were added. After dispersing the water by shaking, the mark cell was repeatedly flushed with the new solution (always reuniting the volume used for rinsing with the stock volume) and finally filled with the new solution. Hence each new solution contained additional $5 \%$ of water

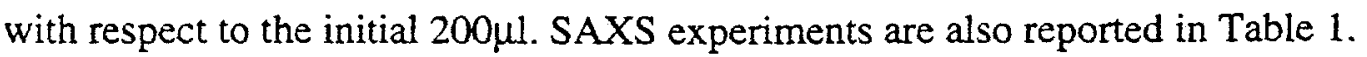

Small angle scattering data were reduced and corrected for background intensity due to instrument dark current, sample container and solvent. Neutron scattering data were placed on an absolute intensity scale by following routine procedures at IPNS (Thiyagarajan, Epperson, Crawford, Carpenter, Klippert \& Wozniak, 1997). Absolute neutron scattering data were further corrected for incoherent scattering from hydrogen, which was calculated from the overall concentration of hydrogen in the respective sample using the numerical value of 80 barns $\left(1 \mathrm{barn}=10^{-24} \mathrm{~cm}^{2}\right.$ ) per atom for the incoherent cross section of hydrogen.

\section{Results and Discussion}

a) OPV-PEG / THF

The SANS data of OPV-PEG solutions in d-THF show a form factor typical of infinitely long, rod-like objects. Hence, modified Guinier analysis for rod-like particles was employed, which involves plotting $\ln [\mathrm{Q} \cdot \mathrm{I}(\mathrm{Q})]$ versus $\mathrm{Q}^{2}$ (Porod 1982). Rod-like particles give rise to a linear region in the modified Guinier plot in the low $\mathrm{Q}$ region $\left(\mathrm{Q}_{\max } \cdot \mathrm{R}_{\mathrm{c}} \leq 1.0\right.$ to 1.3) where the cross sectional radius of gyration of the rod $R_{c}$ can be derived from the slope of the straight line by $R_{c}{ }^{2}=-2 \cdot$ slope. For a rod of homogenous circular cross section the radius of the rod is $R=\sqrt{2} \cdot R_{c}$. Fig. 2 shows the modified Guinier representation of the low-Q scattering data of OPV-PEG solutions in d-THF. The cross sectional radii, $\mathrm{R}$, were calculated according to the above formulae and are reported in Fig.2 and Table 1. The 
agreement of the obtained radii from SANS experiments at different concentrations is reasonable. A close look at Fig. 2 shows that for the higher concentrations of 18 and $24 \mathrm{~g} / \mathrm{l}$ OPV-PEG, the scattering data bend over at very low $\mathrm{Q}$. The effect is more pronounced in the higher concentrated sample and is very likely due to inter-particle interference at higher solute concentrations. This effect accounts for the slightly smaller apparent radii, measured at higher concentrations. The average radius of about $80 \AA$ obtained from the SANS data compares nicely with the approximate length of the OPV block. Given the tendency of OPV to form liquid crystalline structures in THF and the compatibility of PEG with THF, we propose that the giant rod-like aggregates consist of a packed liquid crystalline OPV core and a PEG shell. The block copolymer molecules are oriented perpendicular to the infinitely long axis of the micellar aggregate and the PEG coil is presumably highly swollen by THF. Interestingly, the SAXS experiment yields a considerably larger value of $92 \AA$ for the rod radius. This further supports a model with OPV in the center and PEG in the periphery, since the scattering contrasts of OPV and PEG moieties are practically identical for neutrons, whereas for $\mathrm{x}$-rays, PEG has larger contrast than OPV in THF. (See Table 2 for scattering length densities in all contrast situations encountered in this study.) Based on this hypothesis we attempted to model the scattering objects using 'Biomod' software. A core-shell model was created using 1500 randomly selected scattering centers in each of the moieties. The ideally infinite rod length however had to be limited to $2000 \AA$ due to limitations of the software. It was found that a cylinder with elliptical cross section of 50 and $100 \AA$ length of semi axes gives a much better reproduction of the SANS data than a circular cylinder model. This finding is in agreement with the presumably highly oriented OPV blocks in the cylinder core, which through $\pi$ - $\pi$-interactions probably preserve some degree of liquid crystalline order. The SAXS data were modeled with the same outer semi axes as before and a shell 
thickness of $20 \AA$. Choosing the shell thickness this way, the overall volume of core and shell are similar, which seems reasonable because of the similar molecular volumes of the OPV and PEG moiety. The form factor of the hollow shell was then calculated, thus assuming that in the SAXS case the overwhelming scattering intensity comes from the PEG shell only. Fig.3 shows a comparison of the model form factor with SANS (o) and SAXS (+) data of 18 or 22 g/ OPV-PEG solutions in THF (d-THF for SANS). The dotted line represents the form factor of the full cylinder (SANS contrast), whereas the form factor of the hollow shell (SAXS contrast) is shown as a dot-dashed line. The model reproduces the measured data well. However, the SAXS data at high Q (Fig.3b) deviate significantly from the shell form factor. The hump of the shell model form factor at about 0.06 to $0.1 \AA^{-1}$ is not observed in the SAXS data. This is very likely due to the swelling and disorder of the PEG shell which smears out the shell-shell intra-particle correlation. A further refined model using a more realistic soft PEG shell will be investigated.

b) Influence of water

Fig.4 illustrates the effect of adding $\mathrm{D}_{2} \mathrm{O}$ or $\mathrm{H}_{2} \mathrm{O}$ on the SANS patterns of OPV-PEG solutions containing 24 or $18 \mathrm{~g} / \mathrm{l}$ polymer, respectively. Both $\mathrm{H}_{2} \mathrm{O}$ and $\mathrm{D}_{2} \mathrm{O}$ were used in order to explore different contrast situations. Low water concentrations of up to $8 \%$ have only a small effect on the scattering pattern which can be described as a swelling of the rod. However, when a critical concentration of about $10 \%$ water is reached, a sudden dramatic change in the scattering pattern is observed. At the same time, the former clear solutions turn cloudy (Table 1). The forward scattering intensity rises about one order of magnitude. At the same time, a correlation peak appears at a Q-value which corresponds to the diameter of the above described giant rod-like aggregates. Thus, it appears that the originally distinct rod-like aggregates condense into a phase of packed rods. Further addition of water continuously shifts the peak position to smaller scattering vectors. 
Apparently the phase of packed rods absorbs more water, which leads to a swelling of the OPV-PEG / water phase and increases the mean rod to rod distance. A detailed comparison of the SANS data of sample 3 (with $\mathrm{D}_{2} \mathrm{O}$ ) and sample 4 (with $\mathrm{H}_{2} \mathrm{O}$ ) reveals further interesting details. At high $Q$ sample 4 shows significant additional coherent scattering which obviously arises from $\mathrm{H}_{2} \mathrm{O}$. Since similar scattering is not observed in binary d-THF / $\mathrm{H}_{2} \mathrm{O}$ mixtures, it can be concluded that this signal is due to preferred condensation of water in the PEG moiety of the polymer. Secondly, the correlation peak at intermediate $Q$ is of lesser intensity for sample 4. This is in accordance with a phase of packed rods where water and PEG together form a matrix phase in which OPV cores are embedded. Since the scattering length densities of PEG and $\mathrm{H}_{2} \mathrm{O}$ are similar (when compared to d-THF), effectively inter-particle correlations between adjacent PEG shells will be obscured. Lastly, the strong increase of scattering intensity at very low $Q$ is significantly more pronounced for sample 4. Again this supports the suggested model of a packed OPV-PEG/water phase, since in this case $\mathrm{H}_{2} \mathrm{O}$ will contribute strongly to the coherent scattering signal, whereas $\mathrm{D}_{2} \mathrm{O}$ will not. The SAXS data of sample 5 with increasing amounts of $\mathrm{H}_{2} \mathrm{O}$, shown in Fig.5, further support the model developed so far. In this contrast situation scattering densities of PEG and $\mathrm{H}_{2} \mathrm{O}$ are practically identical. Hence the effect of a reduced correlation peak as observed for sample 4 is even more pronounced. Given the smaller contribution of the inter-rod correlation peak, the SAXS data are well suited to determine the power law scattering at very small $Q$. Determined exponents are reported in Fig.5. The reported concentrations of $\mathrm{H}_{2} \mathrm{O}$ are only approximate due to the volatility of THF and limitations of the mixing procedure described above, which was chosen as a compromise in order to minimize the use of the OPV-PEG diblock copolymer. The magnitude of the observed exponents increases from close to 1 for the initial rod-like aggregates abruptly to greater than 3 , as expected for at 
rough surface of the OPV-PEG/water phase and then decreases and stabilizes close to 2 at high water concentrations. The final exponent of nearly 2 can still be interpreted in different ways, such as an extended sheet-like structure, or a mass fractal aggregate (which is supported by light microscopic studies on dried samples), or flexible Gaussian coiled rods.

\section{Conclusions}

Low molecular weight oligo(phenylenevinylene)-poly(ethyleneglycol) diblock copolymers, OPV-PEG, comprising $13 \mathrm{PV}$ and 45 EG monomers self-assemble in THF into rod-like structures. The cross section of the rods is well described as an elliptical shell with 50 and $100 \AA$ semiaxes and $20 \AA$ shell thickness. The hydrophobic OPV block occupies the inner core, whereas the PEG is located in the periphery of the cross section and is probably swollen by THF. Addition of about $10 \%$ water induces a phase transition of the system. The originally distinct rod-like aggregates condense into a phase of packed rods. Further addition of water leads to a swelling of the OPV-PEG/water phase and finally disrupts the packed phase at water concentrations of about $30 \%$. It is noteworthy from a thermodynamic point of view that any of the binary mixtures of the three components OPV-PEG, THF and water do not phase separate under the same experimental conditions. Many different types of interactions are working together in the ternary system. The $\pi$ - $\pi$-interactions of OPV blocks are likely the dominant driving force for the first assembly of the giant rods. Water then preferably locates in the PEG shells. This in turn induces the formation of the packed rod phase. 


\section{Acknowledgements}

This work was supported by the U.S. Department of Energy, BES-Materials Science, under contract W-31-109-ENG-38. H. H. Wang acknowledges the support from UC/ANL Collaborative Grants and L. Yu acknowledges US AFOSR support. We also wish to thank Soenke Seifert for assistance with the SAXS experiments.

\section{References}

Porod, G. in Small Angle X-Ray Scattering, Chapter 2, O.Glatter, O. \& Kratky, O. Eds. pp.17-51, Academic Press, New York, NY, 1982.

Seifert, S., Winans, R. E., Tiede, D. M. \& Thiyagarajan, P. (1999) J. Appl. Cryst. (This Proceedings).

Thiyagarajan, P., Epperson, J.E., Crawford, R.K., Carpenter, J.M., Klippert, T.E. \& Wozniak, D.G., (1997) J. Appl. Cryst. 30, 280.

Thiyagarajan, P., Urban, V., Littrell, K., Ku, C., Wozniak, D.G., Belch, H., Vitt, R., Toeller, J., Leach, D., Haumann, J.R., Ostrowski, G.E., Donley, L.I., Hammonds, J., Carpenter, J.M. \& Crawford, R.K. (1998), ICANS XIV - The Fourteenth Meeting of the International Collaboration on Advanced Neutron Sources, June 14-19, 1998, Starved Rock Lodge, Utica, Mlinois, Volume 2, 864-878

Wang, H. \& Yu L., J. Am. Chem Soc., submitted 


\section{Tables}

Table 1: List of SANS and SAXS experiments. The volume concentrations of $\mathrm{D}_{2} \mathrm{O}$ and $\mathrm{H}_{2} \mathrm{O}$ were calculated assuming additivity of volumes of PEG/THF solutions and water. Table 2: Scattering length densities for neutrons and $\mathrm{x}$-rays (electron density $\mathrm{x}$ classical electron radius) of the involved components.

\section{Figures}

Fig.1 Chemical structure of the OPV-PEG diblock copolymer.

Fig.2 Modified Guinier Plots of SANS data of OPV-PEG at concentrations of 6, 11, 18 and $24 \mathrm{~g} / \mathrm{l}$ in $\mathrm{d}-\mathrm{THF}$.

Fig.3 SANS (o) and SAXS ( + ) data of OPV-PEG solutions in THF (samples 4 and 5) and comparison with modeled data of a cylindrical shell with elliptical cross section of $30 \mathrm{x}$ $80 \AA^{2}$ inner semi axes and $20 \AA$ shell thickness.

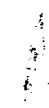

Fig.4 SANS data of OPV-PEG in d-THF with increasing addition of a) $\mathrm{D}_{2} \mathrm{O}$ or b) $\mathrm{H} 2 \mathrm{O}$. For clarity data sets have been shifted by a factor 5 from each other.

Fig. 5 SAXS data of 22 g/ OPV-PEG in THF with increasing addition of $\mathrm{H}_{2} \mathrm{O} . \mathrm{H}_{2} \mathrm{O}$ concentrations are only approximate (see text). For clarity data sets have been shifted by a factor 5 from each other. 


\begin{tabular}{|c|c|c|c|c|}
\hline Sample & OPV-PEG & $\mathrm{D}_{2} \mathrm{O}$ vol\% & $\begin{array}{l}\text { Optical } \\
\text { appearance }\end{array}$ & $\begin{array}{l}\text { Rod Radius } \\
{[\AA]}\end{array}$ \\
\hline 1 & $6.0 \mathrm{~g} /$ & $\ldots$ & clear & $79 \pm 3 \AA$ \\
\hline 2 & $11.0 \mathrm{~g} / 1$ & $\cdots$ & clear & $82 \pm 1 \AA$ \\
\hline \multirow[t]{15}{*}{3} & $24.3 \mathrm{~g}$ & of & clear & $75 \pm 1 \AA$ \\
\hline & & 2.9 & clear & \\
\hline & & 5.7 & clear & \\
\hline & & 8.3 & cloudy & \\
\hline & & 10.7 & translucent & \\
\hline & & 13.0 & translucent & \\
\hline & & 15.3 & opaque & \\
\hline & & 18.4 & opaque & \\
\hline & & 21.3 & translucent & \\
\hline & & 24.0 & translucent & \\
\hline & & 26.5 & TL/cloudy & \\
\hline & & 28.8 & cloudy & \\
\hline & & 31.0 & - clear & \\
\hline & & 33.1 & - clear & \\
\hline & & $\mathrm{H} 2 \mathrm{O}$ vol\% & & \\
\hline \multirow[t]{14}{*}{4} & $18.2 \mathrm{~g} /$ & 이 & clear & $77 \pm 2 \AA$ \\
\hline & & 2.9 & clear & \\
\hline & & 5.7 & clear & \\
\hline & & 8.3 & cloudy & \\
\hline & & 10.7 & translucent & \\
\hline & & 13.0 & translucent & \\
\hline & & 15.3 & translucent & \\
\hline & & 18.4 & translucent & \\
\hline & & 21.3 & translucent & \\
\hline & & 24.0 & translucent & \\
\hline & & 26.5 & TL/cloudy & \\
\hline & & 28.8 & cloudy & \\
\hline & & 31.0 & - clear & \\
\hline & & 33.1 & - clear & \\
\hline \multirow[t]{9}{*}{5 (SAXS) } & $22.4 \mathrm{~g} / \mathrm{l}$ & 0 & & $92.2 \pm 0.3 \AA$ \\
\hline & & 4.8 & cloudy & \\
\hline & & 9.1 & $\ldots$ & \\
\hline & & 13.0 & $\ldots$ & \\
\hline & & 16.7 & -- & \\
\hline & & 20.0 & $\cdots$ & \\
\hline & & 23.1 & $\ldots$ & \\
\hline & & 25.9 & $\cdots$ & \\
\hline & & 28.6 & $\cdots$ & \\
\hline
\end{tabular}




\begin{tabular}{|l|c|c|}
\hline Compound & \multicolumn{2}{|c|}{$\begin{array}{l}\text { Scattering Length } \\
\text { Density }\left(10^{10} \mathrm{~cm}^{-2}\right) \\
\text { Neutrons }\end{array}$} \\
\hline $\mathrm{H}_{2} \mathrm{O}$ & -0.56 & 9.36 \\
\hline $\mathrm{D}_{2} \mathrm{O}$ & 6.36 & -- \\
\hline THF & 0.18 & 8.35 \\
\hline d-THF & 6.35 & - \\
\hline PEG & 0.58 & 9.46 \\
\hline OPV & 0.79 & 8.80 \\
\hline
\end{tabular}




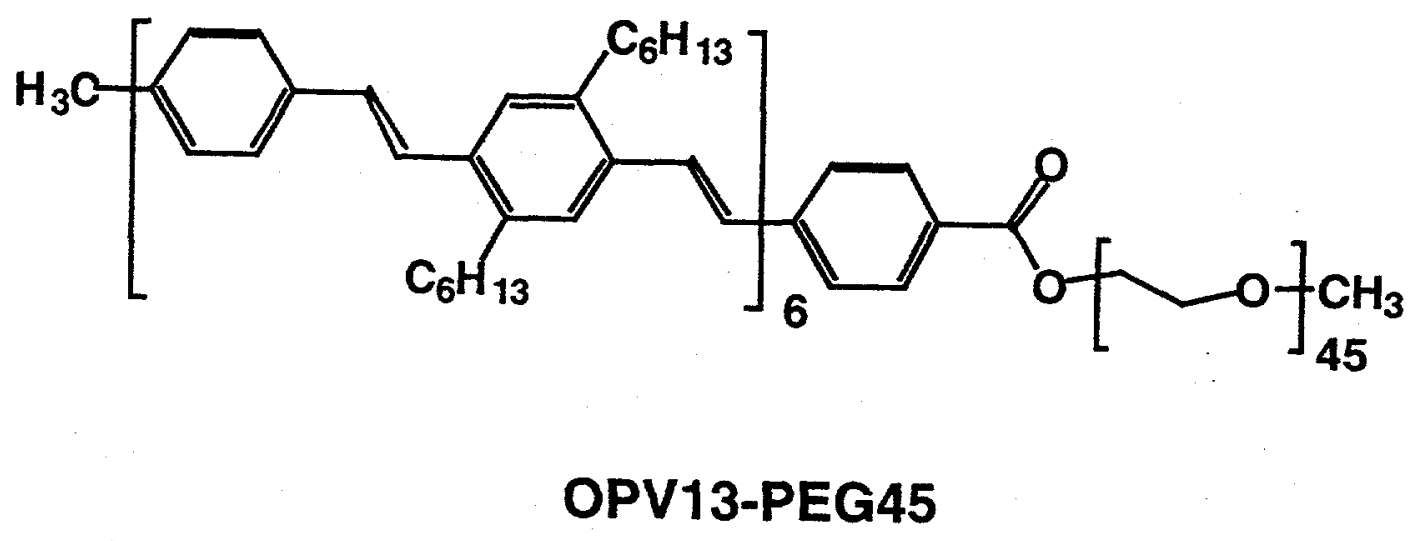




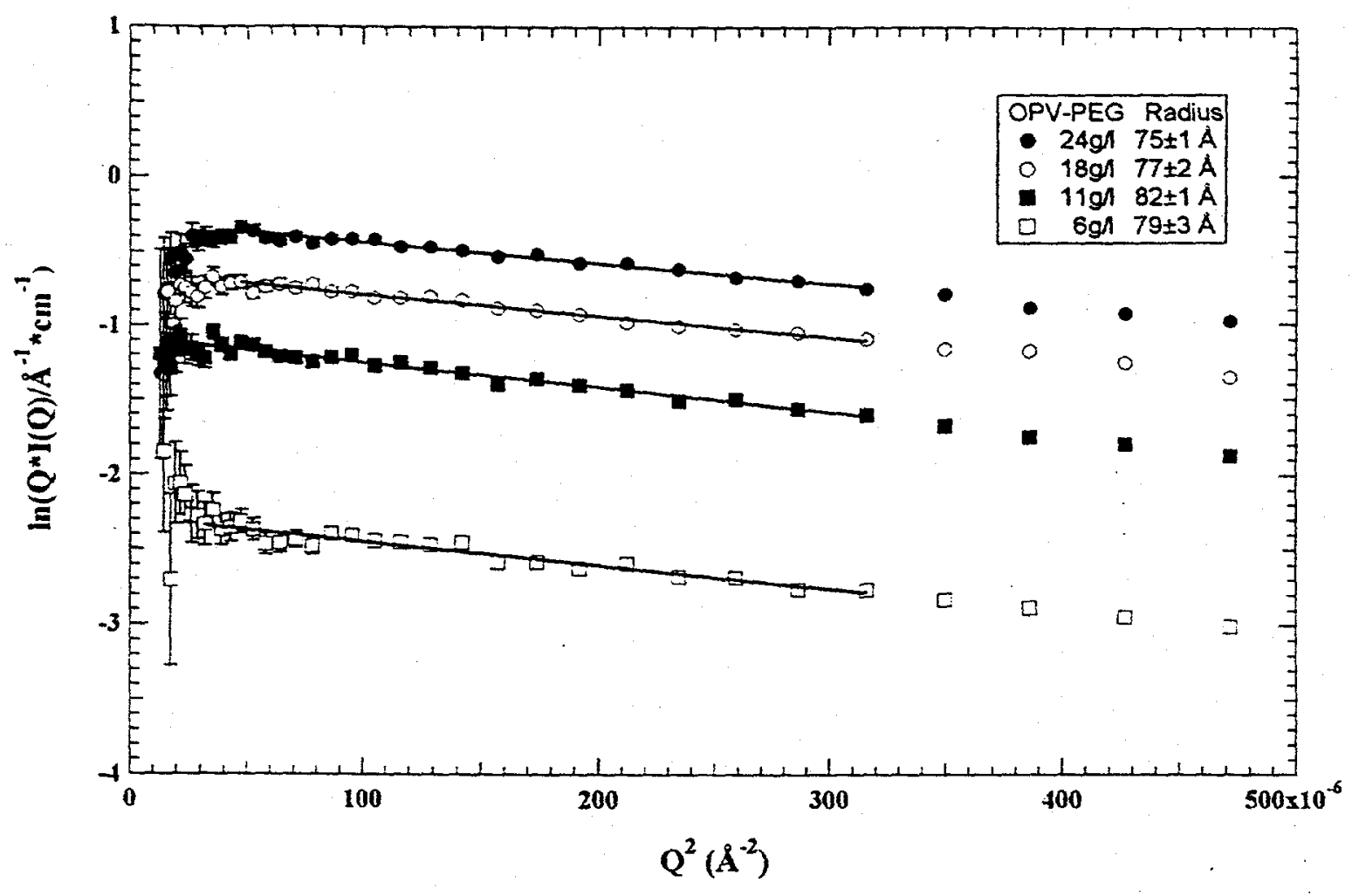




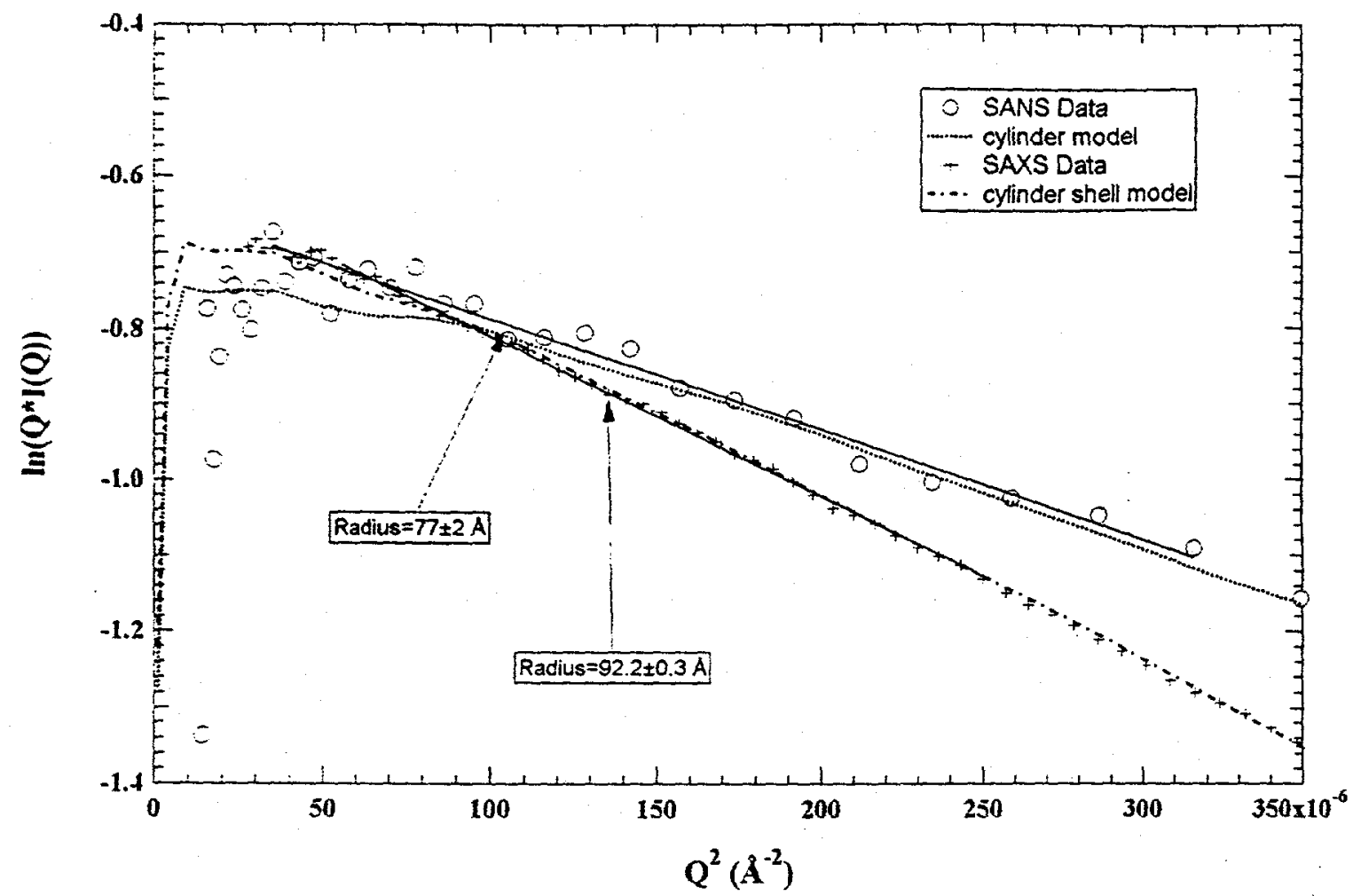

a)

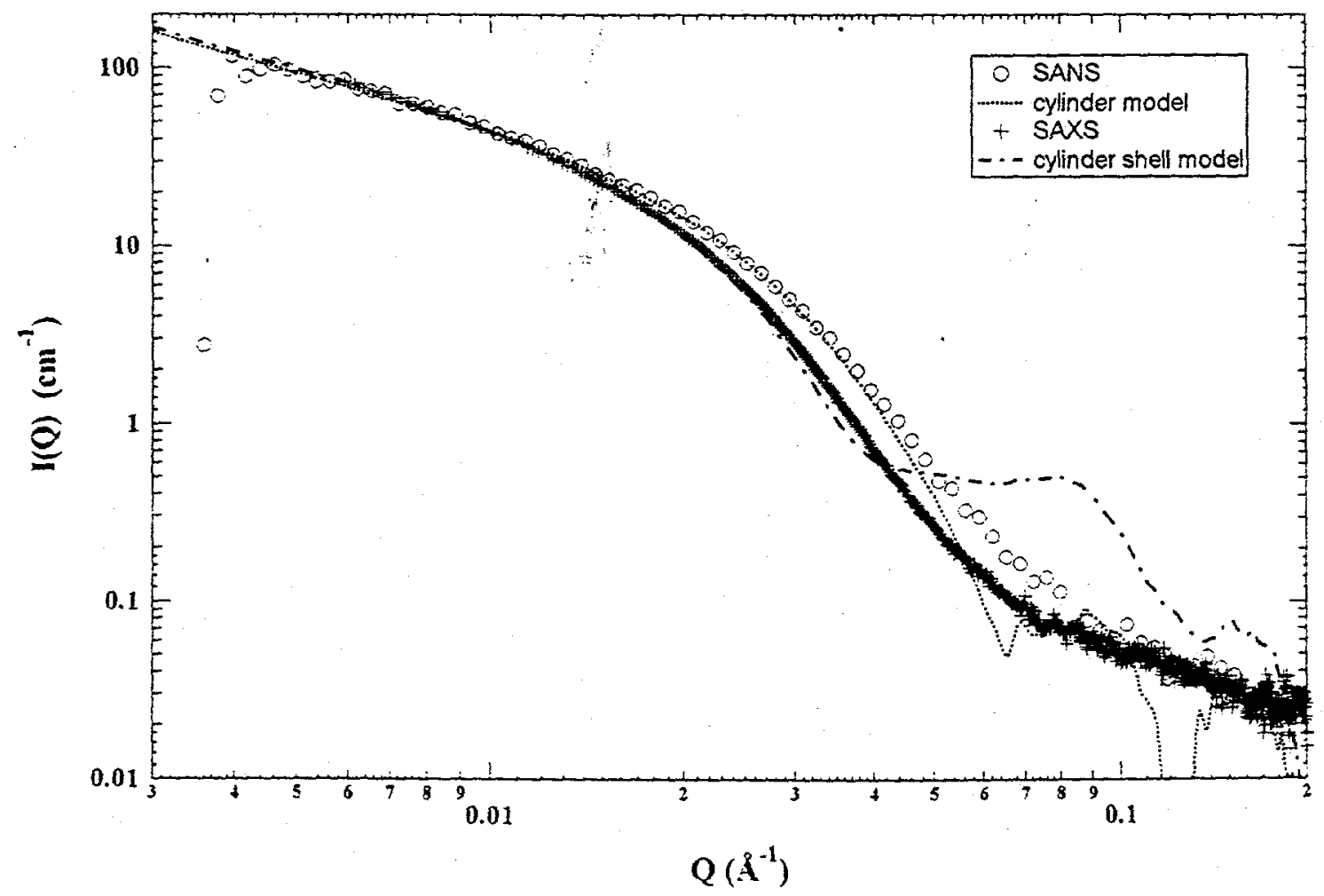

b) 


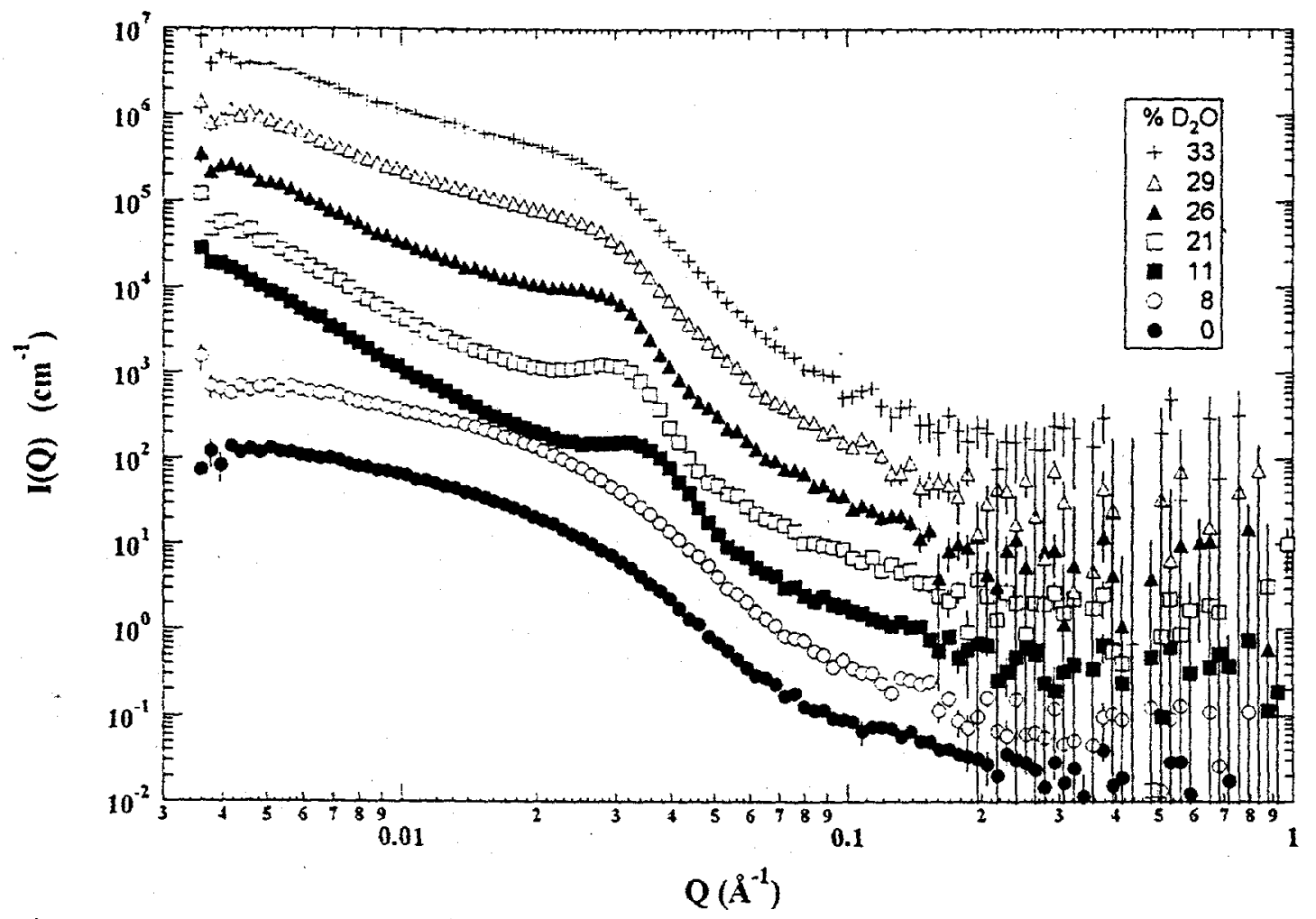

a)

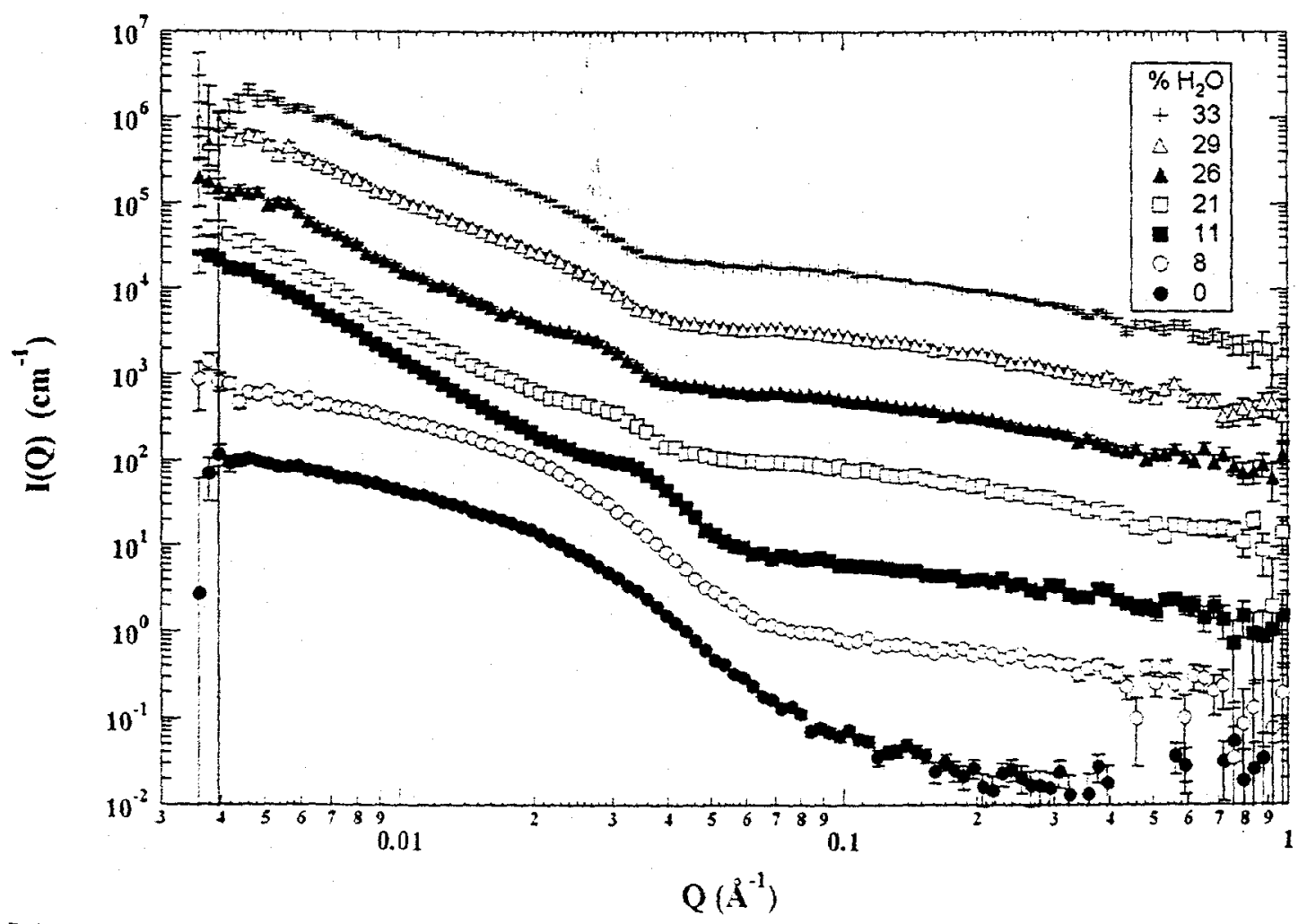

b) 


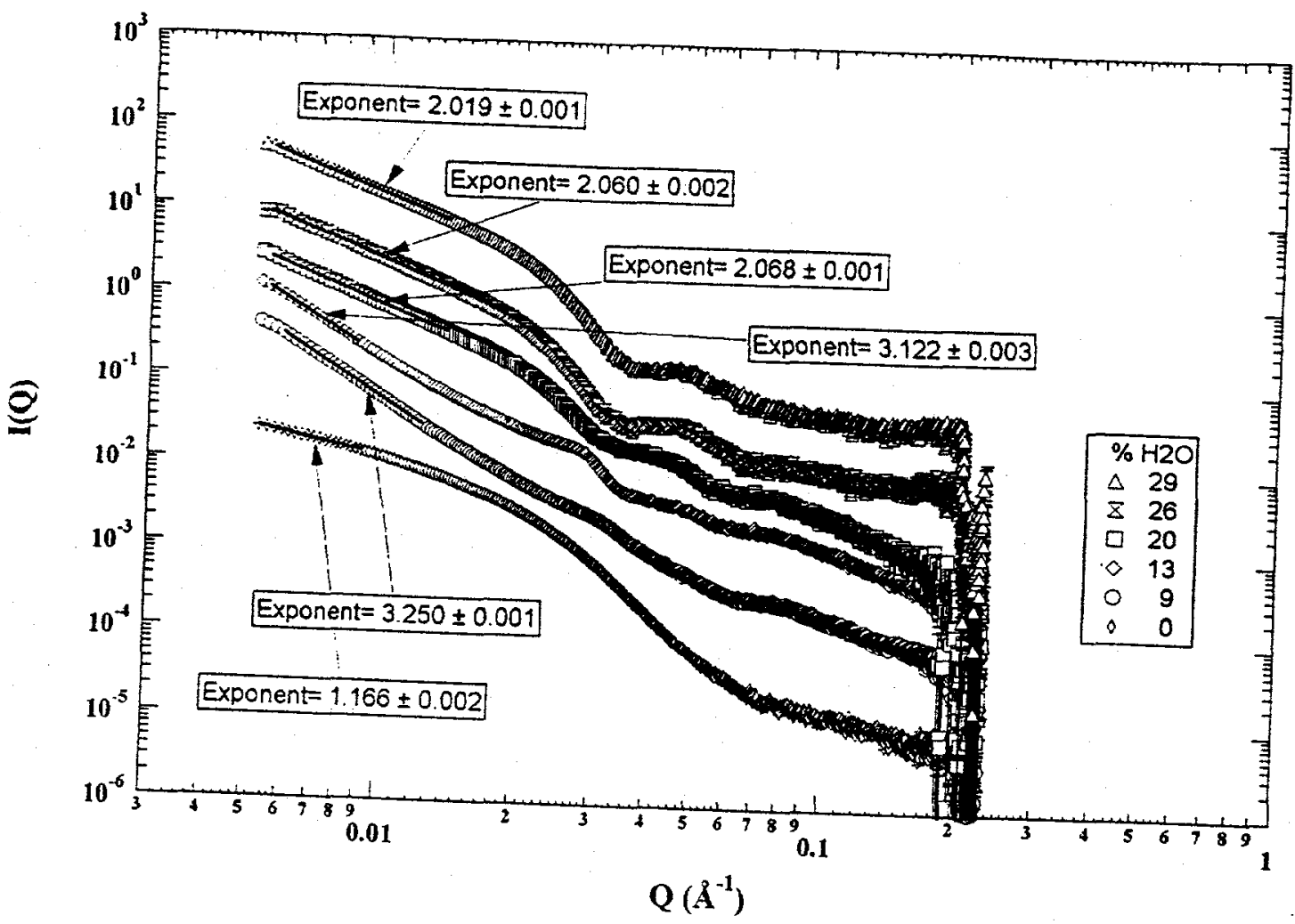

